\title{
Custos da ampliação da licença-paternidade no Brasil
}

\author{
Sergio Almeida* \\ Paula Pereda** \\ Rafael Ferreira**
}

Há uma crescente literatura empírica documentando que educação e cuidado parental de qualidade estão associados com um melhor desenvolvimento emocional e cognitivo da criança. Diante disso, governos de vários países vêm promovendo mudanças nas suas leis trabalhistas, com o objetivo de dar suporte financeiro e legal (proteção do emprego) para as mães e também os pais com crianças recém-nascidas. O Brasil aprovou recentemente o Marco Legal da Primeira Infância (Lei n. 13.257/2016), que ampliou a licença-paternidade de 5 para 20 dias. Pouco se sabe, entretanto, sobre o impacto econômico desse tipo de política pública. 0 presente trabalho procura quantificar os custos intertemporais do custo econômico direto da extensão da licença-paternidade para o Brasil. Para isso utilizam-se microdados da Pesquisa Nacional por Amostra de Domicílios, indicadores do mercado de trabalho brasileiro e uma série de projeções populacionais para construir cenários estáticos para estimativas da probabilidade de os pais solicitarem o uso da licença. Os resultados indicam que a extensão da licença-paternidade para 20 dias tem baixo custo - cerca de $\mathrm{R} \$ 100$ milhões por ano no cenário mais provável, 0 que representa $0,01 \%$ da arrecadação federal em 2014 . Conquanto a magnitude dos benefícios seja ainda desconhecida no Brasil, os resultados sugerem que esse tipo de intervenção será provavelmente custo-efetiva.

Palavras-chave: Licença-paternidade. Primeira infância. Custos.

\footnotetext{
* Departamento de Economia, Faculdade de Economia, Administração e Contabilidade da Universidade de São Paulo (FEAUSP), São Paulo-SP, Brasil (sergio.almeida@usp.br).

** Departamento de Economia, Faculdade de Economia, Administração e Contabilidade da Universidade de São Paulo (FEA-USP), São Paulo-SP, Brasil (pereda@usp.br).

${ }^{\star \star \star}$ Departamento de Economia, Faculdade de Economia, Administração e Contabilidade da Universidade de São Paulo (FEA-USP), São Paulo-SP, Brasil (rafaelferreira@usp.br).
} 


\section{Introdução}

Um amplo conjunto de trabalhos empíricos vem documentando os impactos positivos de intervenções na primeira infância sobre performance escolar e habilidades cognitivo-emocionais (KAROLY; CANNON, 2005; ZIGLER, 2006). Alguns estudos destacam, por exemplo, que a interação inicial do pai com o recém-nascido aumenta o envolvimento dele na educação dos filhos, o que gera efeitos positivos no desenvolvimento sociocognitivo das crianças. Tais efeitos são importantes porque estão associados, na fase adulta, com relativo sucesso socioeconômico.

À luz das potenciais implicações que o cuidado parental na primeira infância pode ter, os governos de vários países vêm promovendo mudanças nas suas leis trabalhistas, no sentido de dar suporte financeiro e legal (proteção do emprego) para as mães e também os pais com crianças recém-nascidas. Segundo o relatório sobre maternidade e paternidade da Organização Internacional do Trabalho (ADDATI et al., 2014), o número de países que concedem o direito à licença-paternidade aumentou de 41 para 79 nas últimas duas décadas. Existe particular resistência a esse tipo de incentivo monetário referente ao envolvimento paterno no cuidado infantil nos principais países do sudeste-asiático, muito embora políticas de apoio à família e ao cuidado infantil venham sendo crescentemente utilizadas por essas nações como forma de mitigar as baixas taxas de fecundidade (FRESKA et al., 2013). Mas, na maior parte dos países que concedem licença-paternidade (71), o benefício é remunerado, sendo majoritariamente pago, nesses casos, pelo empregador. A duração da licença varia de 1 a 90 dias, com as licenças relativamente mais extensas (isto é, mais de duas semanas) sendo observadas em países europeus como Finlândia, Islândia, Lituânia, Portugal e Eslovênia.

No Brasil, até recentemente, os pais gozavam de cinco dias remunerados de licença conforme estipulado nas disposições transitórias da Constituição Federal. Um projeto de lei aprovado no início de 2016 determina uma série de ações voltadas para a primeira infância. Uma importante alteração regulatória introduzida foi a prorrogação da duração da licença-paternidade em 15 dias, além dos cinco já estabelecidos constitucionalmente. ${ }^{1}$

Conquanto haja evidências de que a extensão da licença poderia ter uma série de benefícios, o aumento da sua duração tem custos diretos e indiretos. Os primeiros referem-se ao montante pecuniário a ser desembolsado pelo governo, ou pelos empregadores, para cobrir os rendimentos do trabalhador durante o período da licença. Já os custos indiretos correspondem aos potenciais impactos sobre o mercado de trabalho (salário e nível de emprego). Em teoria, a ampliação dos dias de licença-paternidade aumentaria o custo do trabalhador, uma vez que a produtividade média do empregado diminuiria por conta dos dias em que ficaria ausente do trabalho - além dos custos adicionais de transação que a reposição desse empregado pode trazer para a empresa. Conhecer esses custos é

\footnotetext{
${ }^{1}$ Apenas pais empregados em empresas que participam do Programa Empresa-Cidadã são elegíveis a usufruírem da prorrogação.
} 
de vital importância para uma avaliação mais rigorosa e informada do custo-efetividade do projeto proposto. Embora seja uma informação de clara utilidade para legisladores e agentes públicos interessados no tema, muito pouco se sabe sobre os reais custos que a extensão do benefício teria.

O objetivo desse estudo é estimar os custos diretos até 2030 da ampliação em 15 dias da licença-paternidade para os principais setores da atividade econômica brasileira afetados pela mudança. Supondo que o custo direto da política seja dado pela perda de produtividade das empresas na ausência temporária dos homens que pleitearam tal benefício, construímos uma série de cenários nos quais calculamos o impacto monetário dessa política. Esses cenários combinam projeções sociodemográficas, parâmetros de caracterização do mercado de trabalho e estimativas de probabilidade de invocar o benefício, pois nem todos os pais fazem uso da licença. Não foram considerados os efeitos indiretos sobre salário e nível de emprego no mercado de trabalho. No entanto, dada a magnitude relativamente pequena dos custos encontrados, tudo indica que esses seriam pouco significativos.

Os resultados mostram que o custo direto da política pode variar de $\mathrm{R} \$ 5$ milhões a pouco mais de $\mathrm{R} \$ 100$ milhões, dependendo do cenário considerado. Muito embora a existência de custos por trás desse tipo de política pública seja discutida há tempos na literatura, existe pouca evidência formal de sua real magnitude - o que é tanto mais verdade no contexto brasileiro, dado o caráter recente da inovação. 0 presente trabalho, portanto, complementa essa literatura ao mensurar, a partir de conexões entre aspectos comportamentais e projeções sociodemográficas, limites inferiores para o custo econômico de políticas de apoio parental no mercado de trabalho.

A seguir, apresentam-se a teoria e evidência de custos e benefícios da ampliação da licença-paternidade. Posteriormente é descrita a estratégia metodológica para o cômputo do custo dessa ampliação e discutem-se os resultados. Por fim, são tecidas algumas considerações sobre o estudo.

\section{Impacto da licença-paternidade}

A ampliação da licença-paternidade pode ser vista, em essência, como uma provisão de benefício ao trabalhador pelo empregador. Conquanto seja uma ferramenta interessante de política social - porque financiada sem aumento de receita tributária e a consequente perda de peso-morto da taxação² -, seus efeitos são diversos, em direções nem todas desejáveis. Logo, não é óbvio que a ampliação do benefício seja, em termos líquidos, custo-efetiva. Do ponto de vista teórico, é possível conjecturar que a ampliação da licença-paternidade pode ter pelo menos duas consequências.

\footnotetext{
20 "peso-morto da taxação" está relacionado à redução no volume de transações no mercado de um bem ou serviço qualquer - incluso aí o mercado de trabalho -, produzidas pelo aumento do preço do bem/serviço que a imposição de um imposto engendra.
} 
A primeira é sobre o nível de emprego e salário. Considerando que o empregado valoriza o benefício recebido, é de se esperar que o salário se reduza para compensar o custo do benefício ao empregador. 0 custo de eficiência seria tanto menor quanto mais próximo do tamanho do benefício fosse o ajuste no salário. Esse efeito sobre o salário, todavia, pode não ser observado quando o benefício é dispensado para um grupo demográfico muito específico dentro do ambiente de trabalho e/ou quando há barreiras para que os salários se ajustem para refletir o valor do benefício para o grupo. Se os custos para o empregador da extensão do benefício não podem ser compensados por ajustes nos salários relativos, a extensão do benefício (mesmo que seu uso seja opcional) pode ter um efeito negativo na oferta de trabalho e, por conseguinte, no nível de emprego. Como as leis trabalhistas brasileiras impedem a discriminação salarial e a redução de salários, a extensão do benefício pode afetar o nível de emprego da economia. No entanto, a transmissão desses efeitos para o nível de emprego dependerá do tamanho do custo direto da política, objeto esse da investigação proposta pelo presente estudo.

A segunda consequência é sobre os resultados futuros dos filhos em várias dimensões. Esses são efeitos dinâmicos que podem se manifestar por meio de dois mecanismos causais: o primeiro está relacionado ao tempo adicional que o pai gastará com a criança, já que a interação com os pais tem efeitos positivos no desenvolvimento sociocognitivo da criança (HUERTA et al., 2013); e o segundo compreende o efeito que o tempo adicional despendido pelo pai ajudando a mãe com os primeiros cuidados com o filho terá sobre a probabilidade de dissolução da união durante a fase pré-adulta da criança (COOLS et al., 2015). Há, de fato, evidência empírica de que a licença-paternidade, pelo menos nos países onde foi implementada há mais tempo e possui extensão relativamente mais longa, tem ajudado a promover maior interação dos pais com os filhos recém-nascidos (SEWARD et al. 2002; NEPOMNYASCHY; WALDFOGEL, 2007). Mesmo nos EUA, onde não há nenhuma legislação trabalhista provendo algum tipo de licença remunerada do trabalho por ocasião de adoção ou nascimento de filho, os dados indicam que os pais se envolvem, em um regime compartilhado com as mães, numa série de atividades relacionadas ao cuidado do recém-nascido (TANAKA; WALDFOGEL, 2007).

É compreensível, todavia, um certo agnosticismo com os efeitos esperados da extensão da licença por meio do primeiro canal. Mesmo havendo evidências de que interações entre pais e filhos sejam importantes para o desenvolvimento cognitivo da criança, uma extensão curta da licença-paternidade poderia não ser suficiente para provocar esse tipo de efeito. A extensão proposta, contudo, tornaria o prazo da licença similar ao de alguns países onde a literatura acadêmica encontrou evidências de que a interação entre pais e filhos trouxe benefícios que persistiram ao longo da adolescência e da vida adulta dos filhos (HUERTA et al., 2013). Na Espanha, por exemplo, verificou-se que a introdução de uma licença-paternidade de 13 dias foi extensa o suficiente para induzir, de forma causal, um aumento na demanda dos pais pelo benefício (ESCOT et al., 2013). 
Muito embora nossa análise concentre-se na estimação dos custos monetários diretos que a extensão da licença-paternidade traria, é informativo - e útil para fins de referência fazer um apanhado da literatura empírica existente voltada para a investigação dos efeitos da licença-paternidade. Assim, a seguir, apresenta-se um sumário dessa literatura, iniciando com aquela acerca dos efeitos sobre o mercado de trabalho, para, em seguida, focar na literatura empírica sobre os benefícios da licença nos países onde ela é relativamente mais generosa (sobretudo em termos de extensão) e/ou foi implementada há mais tempo.

\section{Custos da licença-paternidade}

Apesar de haver uma extensa literatura sobre os impactos da licença-maternidade sobre mercado de trabalho, ainda é escassa a literatura avaliando o efeito do benefício homólogo para os pais (GRUBER, 1994; BAUM, 2003; BAKER; MILLIGAN, 2008; LEQUIEN, 2012). Não obstante, é de se esperar que o impacto da licença-paternidade sobre a performance dos homens no mercado de trabalho seja análogo ao da licença-maternidade sobre o desempenho das mulheres, com a ressalva, obviamente, de que a magnitude do custo imposto às mulheres tende a ser maior, dada a diferença entre os benefícios previstos em lei.

Desse modo, analisar os impactos da licença-maternidade sobre o mercado de trabalho feminino pode ser informativo quanto aos efeitos esperados da ampliação da licença-paternidade.

Grande parcela da literatura empírica que avalia esses impactos parte de experiências de países que mudaram as regras que regem a concessão de benefícios. A França, por exemplo, realizou em 1994 uma mudança nas regras de concessão de incentivos financeiros a pais de recém-nascidos. Lequien (2012) encontra evidências de que a adoção da política induziu as mães a se retirarem do mercado de trabalho nos três anos após o nascimento do filho, sendo que a duração do período tem um impacto negativo no salário após o retorno ao trabalho. Parte desta redução está associada ao menor número de horas trabalhadas por dia.

Esses resultados são parcialmente diferentes daqueles encontrados por Ruhm (1996), ao estudar o efeito da licença para as mulheres no mercado de trabalho, em 16 países europeus, entre 1969 e 1988 . 0 autor observa que o direito à licença paga para as mulheres provoca aumento da porcentagem de mulheres empregadas (mesmo no caso em que a licença máxima seja de três meses), sendo de cerca de $4 \%$ para todas as mulheres e $9 \%$ para aquelas com recém-nascidos. Para licenças curtas, o efeito sobre o salário é quase nulo. Porém, conforme o período da licença se amplia para seis meses ou mais, o salário diminui entre 1,5\% e 3\%. Apesar de Ruhm (1996) encontrar efeito quase nulo sobre o salário para licenças curtas, Baker e Milligan (2008) encontram evidências de que, mesmo nesses casos, a licença contribui para reduzir o abandono do emprego e aumentar a proporção de mães que retornam para o mesmo emprego ocupado antes do parto.

Outra alteração legal também estudada na literatura é a adoção do Family and Medical Leave Act de 1993, nos Estados Unidos, que estabeleceu a licença compartilhada e garantiu estabilidade no emprego. Han et al. (2009) analisam como essa nova lei afetou os pedidos 
de licença, observando que estes variam com o sexo, educação e estrutura familiar. Para as mulheres, as licenças cresceram de $5 \%$ para $9 \%$, enquanto para os homens as faltas ampliaram-se em $4 \%$, mas o resultado é significante somente para o mês de nascimento. 0 aumento nos pedidos de licença só é significante para pais com maior nível educacional e é superior para mulheres casadas.

Com relação às evidências sobre a licença-paternidade, nos países nórdicos - que são aqueles em que os benefícios são mais extensos - Haataja et al. (2009) abordam a frequência com que os homens residentes nesses países requisitam a licença-paternidade e a participação do pai na licença compartilhada. Os resultados mostram que pais finlandeses são os que mais a requisitam, mas também os que utilizam o menor tempo na licença compartilhada, sendo que na Islândia a participação é maior.

Com foco específico na Noruega, Cools et al. (2015) não encontram evidências de que a licença afeta o salário e as horas trabalhadas dos pais, nem efeito nas horas trabalhadas da mulher, apesar de observarem um aumento da participação do homem em casa. Rege e Solli (2013) também utilizam dados da Noruega, mas para investigar o efeito da licença-paternidade sobre os rendimentos de longo prazo dos pais. Partindo de uma lei de 1993, que instituiu o direito paterno a quatro semanas de licença remunerada para cuidar de seu filho, os autores verificam que a licença reduz os rendimentos futuros dos pais, sendo que esse efeito persiste até o último ano do período de observação, quando a criança atinge cinco anos. Além disso, seus resultados não apontam para um aumento da participação da mulher no mercado de trabalho em decorrência de uma licença-paternidade mais longa, como indicava a literatura.

Para o Brasil, o estudo empírico mais significativo é o de Carvalho (2005), que verifica o impacto da mudança da licença-maternidade, que passou de 12 semanas para 120 dias na Constituição Federal de 1988, sobre o mercado de trabalho das mulheres. Utilizando dados da Pesquisa Mensal de Emprego (PME) de 1986 a 1991, o autor observou que a licença não impôs impactos significativos sobre salários. Também não foram encontrados indícios de que tenha ocorrido aumento na retenção das mulheres no mercado de trabalho, mesmo para o grupo das mais escolarizadas.

\section{Benefícios da licença-paternidade}

Já existe uma vasta literatura acadêmica indicando os benefícios da licença-maternidade. A legislação sobre o benefício para as mulheres vem sendo experimentada em vários países desde o fim dos anos 1970. Os benefícios da licença-paternidade, todavia, ainda não são tão extensamente documentados como no caso materno. Isso ocorre, essencialmente, por duas razões. Primeiro porque os efeitos desse tipo de mudança estatutária podem não ser ainda completamente visíveis. A julgar pela evidência para a situação materna, há razões para acreditar que alguns dos benefícios dependem da extensão do período de licença, que é ainda relativamente curto na maioria dos países vis-à-vis a duração do benefício materno. Segundo, porque a mensuração exata desses efeitos envolve o uso de dados que 
incluem informação de influências concorrentes (chamados na literatura de confounding effects) sobre as variáveis de interesse, que nem sempre estão disponíveis. Ainda que a literatura seja escassa, há um conjunto de estudos que procuram avaliar o impacto do envolvimento paterno no cuidado do recém-nascido. Esses trabalhos oferecem, portanto, uma ideia preliminar do tipo de benefício esperado da extensão da licença-paternidade. Ainda que focada em uma variedade de aspectos, a literatura empírica sobre os benefícios da licença-paternidade pode ser dividida em dois grandes tópicos: desenvolvimento infantil; e igualdade de gênero.

Comecemos tratando dos benefícios relacionados ao desenvolvimento infantil. A literatura cita alguns mecanismos pelos quais um maior tempo de convivência entre pai e filhos recém-nascidos poderia trazer benefícios nesse aspecto. Flacking et al. (2010), por exemplo, conjecturam que a licença facilitaria a divisão das responsabilidades entre o casal e, por conseguinte, o trabalho de amamentação por parte da mãe. Os autores investigam a relação entre o uso da licença-paternidade e a duração da amamentação no primeiro ano de vida das crianças. 0 estudo utiliza dados de quase 52 mil crianças e encontra evidências de que as crianças dos pais que não fizeram uso da licença-paternidade tinham uma maior probabilidade de não serem amamentadas no primeiro ano, vis-à-vis os filhos dos pais que utilizaram a licença. Os benefícios da amamentação são hoje conhecidos e bem documentados na literatura médica. No Brasil, Victora (2005) verifica o efeito da duração da amamentação no nível educacional dos indivíduos homens e encontra uma relação significante entre o maior nível educacional e a duração da amamentação. Aqueles indivíduos que foram amamentados por nove meses ou mais estavam de 0,5 a 0,8 ano à frente daqueles que foram amamentados menos de um mês, o que corresponde a uma diferença de $10 \%$ a $15 \%$ na renda futura dos adultos. Já em estudo mais atual, Victora (2015) investiga os efeitos da amamentação no longo prazo, observando correlação positiva entre a duração do período de amamentação e o coeficiente de inteligência (QI), com a continuidade dos estudos e com a renda dos indivíduos. Isto é, as pessoas que foram amamentadas 12 meses ou mais possuíam maior QI (diferença de 3,76 pontos), mais anos de educação $(0,91$ ano) e maior renda ( $R$ \$ 341) do que aquelas que foram amamentadas por um mês ou menos.

Há também estudos com evidências dos benefícios mais diretos do envolvimento paterno no desenvolvimento infantil. Huerta et al. (2013), por exemplo, investigam a relação entre envolvimento paterno e desenvolvimento cognitivo e comportamental da criança, encontrando uma associação positiva entre envolvimento paterno e a performance das crianças em alguns testes cognitivos, mas apenas quando tal envolvimento diz respeito às atividades de leitura e brincadeira com a criança, sendo mais forte quando a interação paterna ocorre no segundo e no terceiro ano de vida da criança. Essa associação positiva, todavia, não é verificada quando a interação com o pai inclui apenas os cuidados mais comuns com a criança - troca de fraldas, alimentação e colocar a criança para dormir.

Há mesmo evidência de que esses efeitos da interação com os pais no desenvolvimento infantil podem ser modulados por uma série de aspectos. Em estudo com dados 
censitários da Noruega, Cools et al. (2015) verificam que a performance escolar de filhos de pais que fazem uso da licença-paternidade é melhor, mas somente se a escolaridade do pai for maior do que a da mãe.

Assim, vários estudos mostram, sem ambiguidade, que a licença-paternidade, sobretudo quando atraente para os pais e quando não pode ser transferida para a esposa, promove o maior envolvimento dos pais no cuidado dos filhos de forma duradora. Dados indicando que o aumento do benefício e a redução das restrições de elegibilidade aumentaram sistematicamente a taxa de pais elegíveis que requerem o benefício podem ser encontrados em Marshall (2008), Philips (2004) e O’Brien (2009). Há evidência de que esse envolvimento paterno se estenderia para além dos cuidados dispensados durante o período de licença. Nepomnyaschy e Waldfogel (2007), por exemplo, trazem resultados em linha com essa conclusão. Utilizando dados de uma pesquisa com os pais de mais de 10.000 mil crianças nascidas nos Estados Unidos em 2001, os autores encontraram uma correlação positiva entre a duração do afastamento do trabalho após o nascimento ou adoção da criança e o envolvimento e interesse paterno no cuidado com a criança nove meses depois.

O segundo principal conjunto de benefícios potenciais decorrentes da licença-paternidade diz respeito à igualdade de gênero. De acordo com a teoria econômica, a concessão de benefícios trabalhistas que sejam fonte de custos aos empregadores tenderia, tudo mais constante, a reduzir o nível de emprego e o salário dos trabalhadores. Seria razoável esperar, portanto, que a possibilidade de afastamento remunerado do trabalho após o nascimento de um filho ou de uma filha tenha impacto negativo sobre a renda do trabalhador. 0 problema emerge da assimetria entre mulheres e homens quanto aos benefícios a que têm direito: a licença-maternidade permite o afastamento remunerado do trabalho por seis meses, ao passo que a licença-paternidade possibilita menos dias. 0 diferencial de gênero na extensão da licença tende a prejudicar mulheres no mercado de trabalho, ao diminuir sua empregabilidade e contribuir para a ampliação do diferencial de salário em relação aos homens.

0 aumento da duração da licença-paternidade ajudaria, portanto, a reduzir a diferença entre homens e mulheres nesse particular, mesmo que marginalmente. Existe, de fato, algum suporte empírico para esse efeito na literatura científica. Rege e Solli (2013), por exemplo, concluem que os pais que fazem uso da licença-paternidade observam uma retração nos seus rendimentos que pode variar entre $1 \%$ e $3 \%$ ou entre $1,8 \%$ e $4,8 \%$, a depender da especificação do modelo econométrico estimado. Esses resultados são persistentes, de modo que permanecem durante todo o período analisado (os cinco primeiros anos após o nascimento da criança). Entretanto, os autores não encontraram efeitos significativos sobre a oferta de trabalho das mulheres. Cools et al. (2015) também analisam o efeito da licença-paternidade sobre o mercado de trabalho e obtêm resultados semelhantes: um efeito negativo - porém não significante - da licença-paternidade sobre o rendimento dos homens. Mais surpreendente, contudo, é o efeito negativo - e significante - da licença-paternidade sobre o rendimento das mães. 
Os efeitos da licença-paternidade métricas de igualdade de gênero - incluindo diferenças salariais entre homens e mulheres - são também o foco de Gislason (2007). Em 2000, a Islândia reformou sua legislação de licença-compartilhada, de modo a aumentar o uso da licença pelos pais. 0 autor enumera uma série de indícios que mostram que a mudança realizada aumentou o tempo de envolvimento do pai com os filhos recém-nascidos, promoveu uma divisão mais equilibrada de responsabilidades entre o casal, elevou a taxa de fecundidade e ajudou a mitigar o diferencial salarial entre homens e mulheres (sobretudo as casadas) causado pela percepção de que as demandas da maternidade cairiam mais pesadamente sobre as mulheres, tornando-as, portanto, menos disponíveis para os compromissos do trabalho. Thor Arnarson e Mitra (2010) encontraram resultados semelhantes. No caso do Brasil, em particular, em que a conciliação entre trabalho e vida familiar ${ }^{3}$ é ainda mais difícil para mulheres do que nos países nórdicos, a ampliação da licença-paternidade poderia ter efeitos importantes.

Há ainda outras formas pelas quais a licença-paternidade poderia, em tese, impactar a performance das mulheres no mercado de trabalho, sendo que uma delas envolve a frequência no trabalho. Ugreninov (2013), por exemplo, investiga se a extensão do benefício na Noruega teve impacto sobre a taxa de absenteísmo por doença das mulheres no trabalho. A hipótese subjacente é a de que ao menos parte desse absenteísmo estaria relacionada ao ônus, sobre as mulheres, de combinarem trabalho com as obrigações do início da maternidade. Os resultados do artigo, todavia, não corroboram essa hipótese - a extensão da licença para sete semanas, com cota de quatro para os pais, não afetou o absenteísmo das mulheres por doença.

Outra forma seria na dinâmica do casal na administração das tarefas familiares e domésticas. Argumenta-se, por exemplo, que uma maior presença do pai nos primeiros dias de vida da criança poderia mudar o comportamento das famílias quanto à divisão de tarefas domésticas. Alguns trabalhos empíricos trazem evidências que dão suporte a esse argumento. Kotsadam e Finseraas (2011), também observando o caso norueguês, encontram indícios de que a reforma diminuiu a desigualdade de gênero no ambiente familiar. Dentre os principais resultados do estudo, verifica-se que pais que tiveram filhos depois da reforma têm um nível $11 \%$ menor de conflitos por questões relacionadas à divisão do trabalho doméstico e uma probabilidade $50 \%$ maior de dividir as tarefas de lavar as roupas, em comparação com pais que tiveram filhos antes da reforma. Os autores não encontraram diferenças significativas entre os dois grupos, no entanto, nos efeitos de longo prazo sobre a atitude geral quanto à igualdade de gênero.

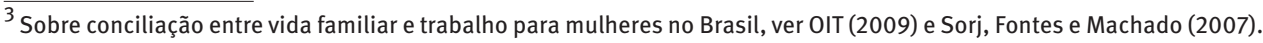




\section{Metodologia para o cálculo do custo direto}

Esta seção descreve a estratégia de estimação utilizada para computar o custo direto da ampliação da licença-paternidade de 5 para 20 dias. Nossa estimativa de custo direto mede o valor total da produtividade perdida pela empresa durante o período em que 0 trabalhador goza da licença-paternidade. Supondo-se que o salário é uma boa aproximação da produtividade do trabalhador, tal perda será, portanto, aproximada pela massa salarial que seria percebida durante o período de licença. Essa é uma estimativa do ônus monetário que recairá sobre o governo federal, uma vez que as empresas com apuração de lucro real podem deduzir do imposto de renda devido exatamente o total da remuneração paga aos empregados usuários da licença.

A estimativa do custo anual referente à extensão da licença-paternidade envolve essencialmente quatro passos. Primeiro, determinar o número de indivíduos na população economicamente ativa do sexo masculino formalmente ocupados (POF). Segundo, determinar dentro desse grupo os indivíduos que serão pais com alguma probabilidade positiva $(P F)$. Esse subgrupo populacional constituiria o conjunto de indivíduos elegíveis à licença-paternidade. Terceiro, determinar a probabilidade de os indivíduos requisitarem o benefício $(\tau)$. A partir dessas informações, é possível computar o número de benefícios a serem concedidos em um dado ano. Então, com informações sobre o salário desses indivíduos ( $S M)$, o quarto passo consiste em produzir estimativas confiáveis sobre o impacto, em termos de custos $(C D)$, que a extensão por 15 dias do benefício $(\triangle)$ teria para empresas cidadãs $(E C)$. A fórmula a seguir resume os elementos de cálculo descritos:

$C D=\tau \times \sum_{i}\left(P F_{i} \times P O F_{i} \times S M_{i} \times \Delta \times E C\right)$

Em que: $i$ representa os grupos etários considerados nas estimativas (na faixa de 15 a 65 anos).

Utilizam-se os dados das Pesquisas Nacionais por Amostra de Domicílio (PNAD) do IBGE de 2008 a 2013, ${ }^{4}$ das Projeções Populacionais oficiais do IBGE de 2014 a 2030, ${ }^{5}$ revisão de 2013, da Síntese dos Indicadores Sociais (SIS) de 2008 a 2013 do IBGE, ${ }^{6}$ assim como dados gerais do Ministério do Trabalho e da Receita Federal do Brasil. A seguir, descrevem-se as etapas do cálculo e os ajustes necessários.

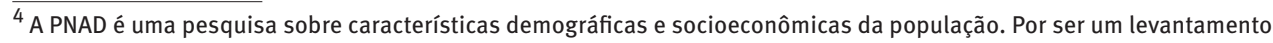
amostral, todos os resultados foram expandidos pelo peso amostral disponibilizado pelo IBGE.

${ }^{5}$ As projeções populacionais mostram o tamanho da população ao longo do tempo por idade e sexo, considerando as taxas de natalidade e mortalidade, imigrações e emigrações.

${ }^{6}$ A SIS é uma publicação que reúne múltiplas informações sobre a ampla realidade social do país.
} 


\section{Probabilidade de serpai}

Nossa estratégia para estimar a probabilidade de ter um/a filho/filha em um dado ano, uma aproximação realizada com os dados disponíveis, segue, essencialmente, três etapas. Primeiro, utilizando os dados da PNAD, estimou-se a distribuição das idades em que os homens foram pais na população brasileira a partir da informação idade dos filhos ${ }^{7}$ que moram na mesma residência que a pessoa de referência do domicílio, ou seja, seus prováveis pais. Para encontrar a distribuição de idade dos pais no momento de nascimento dos filhos, consideraram-se apenas os filhos que residem com o pai, que é a pessoa de referência do domicílio. Não foram incluídos os pais de filhos que moram exclusivamente com as mães, pois neste caso não é possível identificar o pai. Há, no entanto, uma subestimação do percentual de pais entre 16 e 24 anos no momento do nascimento do filho e uma superestimação do percentual de pais entre 25 e 36 anos no momento do nascimento do filho, dadas por não se considerarem pais declarados como cônjuges do domicílio. Entretanto, em análises de sensibilidade, verifica-se que a distribuição etária muda muito pouco: -0,121 p.p., em média, para o primeiro grupo etário; e +0,076 p.p., em média, para o segundo grupo. Vale ressaltar que este possível viés impacta somente a distribuição de idade e não a estimativa da probabilidade de ser pai, que leva em conta todos os indivíduos que foram pais nos últimos 12 meses da pesquisa. Também existe uma subestimação por considerarem-se somente filhos sobreviventes, e não todos os nascidos vivos. Para reduzir essa subestimação, apresenta-se uma correção, também aproximada, descrita no artigo. Após estas considerações, foi construída uma base de dados combinando os filhos com seus respectivos pais e subtraiu-se a idade do pai da idade do filho de cada par pai-filho. Assim, obteve-se a distribuição de idades em que os homens (responsáveis pelos domicílios) foram pais.

O segundo passo envolveu verificar, dentro desse universo, os homens que têm filhos e fazem parte da População Economicamente Ativa $(P E A)^{8}$ e que a idade do filho seja igual a 0 ano (menos de um ano de idade). Essa conjunção de dados significa que o homem selecionado foi pai nos 12 meses anteriores à realização da pesquisa. Além de ter tido filho nesse período, é necessário que o homem faça parte da PEA. Com isso, é possível montar a distribuição, por faixa etária, dos pais que tiveram filhos naquele período e que estão na força de trabalho, ainda que com algumas aproximações necessárias.

Por fim, esse valor foi corrigido usando dados de mortalidade infantil (de 0 a 1 ano) que constam nas projeções populacionais do IBGE, para que a estimativa resultante represente a probabilidade de ser pai de nascidos vivos, e não apenas a probabilidade de ser pai de uma criança sobrevivente. Ressalta-se que, ao número de crianças sobreviventes em cada ano, foi somado o número obtido a partir das estimativas de mortalidade infantil do IBGE

\footnotetext{
7 Deve-se ressaltar que filhos/filhas, conforme coletado nas PNADs, podem ser filhos biológicos, adotivos ou enteados (filhos somente do cônjuge).

${ }^{8}$ A PEA é composta por pessoas classificadas como ocupadas ou desocupadas no período de referência.
} 
(de 0 a 1 ano), ponderado pela frequência relativa de paternidade em cada faixa etária. A partir daí, obtém-se uma estimativa para o número de pais, em cada faixa etária da PEA, não apenas de nascidos sobreviventes, mas também dos nascidos vivos. Ressalta-se que este valor é aproximado, por usar um indicador aproximado da probabilidade de sobrevivência e também por ser uma média nacional, que não inclui as desigualdades regionais da mortalidade entre 0 e 1 ano de vida.

Optou-se pelo uso dos microdados da PNAD, pois essa pesquisa permite relacionar a idade do pai com o requerimento de licença remunerada, assim como comparar o requerimento de licenças remuneradas por outros indivíduos da amostra, que não foram pais no período de coleta dos dados. O Sistema de Informações sobre Nascidos Vivos (Sinasc), da Secretaria de Vigilância da Saúde, Ministério da Saúde, ${ }^{9}$ e as Estatísticas do Registro Civil, do IBGE, ${ }^{10}$ disponibilizam dados detalhados sobre a mãe e o bebê nascido vivo, mas não trazem informações sobre o pai, exceto o local de nascimento e sua idade.

Como foram usados os dados das pessoas de referência no domicílio, um problema que surge é a maior sub-representação dos homens de 15 a 19 anos, que podem ter tido um filho, mas não são a pessoa de referência no domicílio, pois ainda moram com seus pais. Para minimizar este problema, utiliza-se o total de pais com filhos de 0 ano no ano da pesquisa, obtido na amostra da PNAD, e realiza-se uma nova distribuição com base na distribuição da idade em que os homens são pais no Brasil.

Esses exercícios foram realizados para as PNADs de 2008 a 2013. Para os cálculos finais, considerou-se a média de todos os anos (2008 a 2013) como uma estimativa da probabilidade final de os homens terem filho em todos os anos da projeção por faixa de idade. Para verificar a qualidade dos resultados obtidos, comparou-se quanto seria a população de um ano de idade em 2014 - com base na probabilidade de ter um filho estimada em 2013 - com o número de nascimentos registrados no Sinasc em 2014. Pela probabilidade de ter um filho estimada neste exercício, deveria haver 2.934.263 crianças nascidas vivas no Brasil em 2014. Pelo Sinasc, foram registradas 2.979.259 crianças nascidas vivas em 2014. ${ }^{11}$ Portanto, a diferença existente entre a probabilidade estimada e a informação do Ministério da Saúde foi de 1,5\%.

\section{Projeção da população elegível}

Para estimar a população ocupada no setor formal da economia em cada ano, é preciso obter informações sobre a taxa de desocupados e sobre o percentual de trabalhadores da PEA que estão inseridos no setor formal, assim como o total de pessoas do sexo masculino em cada faixa etária $(i)$ e período $(t)$. Logo, a fórmula utilizada para o cálculo foi:

\footnotetext{
$\overline{9}$ Veja as notas metodológicas da pesquisa em: 〈http://tabnet.datasus.gov.br/cgi/sinasc//Nascidos_Vivos_1994_2012.pdf〉.

${ }^{10}$ Veja informações sobre a pesquisa em: 〈http://www.ibge.gov.br/home/estatistica/pesquisas/pesquisa_resultados. php?id_pesquisa=10〉.

${ }^{11}$ Tendo em vista que, mundialmente, os dados de pesquisas domiciliares apresentam sub-registro de crianças (CHACKIEL; ORELLANA, 1985), que os dados das projeções apresentam problemas de estimação e que o Sinasc tem problemas de subregistro, o resultado encontrado com a metodologia aplicada parece ser bastante coincidente e plausível.
} 
$C P O F_{i}^{t}=(1-T D) \times P S F \times P T_{i}^{t}$

Em que:

POF: população ocupada masculina no setor formal;

$(1-T D)$ : percentual de ocupados;

PSF: porcentagem de pessoas no setor formal da economia;

$P T$ : população total masculina estimada pelo IBGE.

Ao substituir a população de 2013 na fórmula (2), tem-se a população ocupada masculina no setor formal para este ano. Com a probabilidade de ter um filho em determinado ano e a população ocupada no setor formal da economia, chegou-se ao conjunto de homens que poderão requerer o benefício da licença-paternidade, denominado "população elegível”. O Gráfico 1 apresenta a estimativa da população elegível a solicitar a licença-paternidade por grupos de idade para 2013.

GRÁFICO 1

Estimativa da população masculina apta a solicitar licença paternidade de 20 dias (população elegível), por grupos de idade

Brasil - 2013

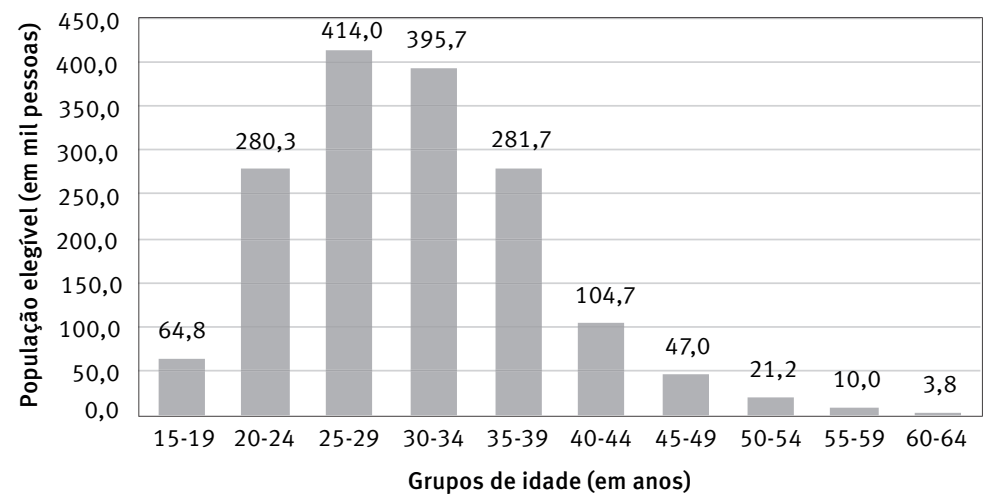

Fonte: IBGE. PNAD 2013 e Estimativa de População 2013; Ministério da Saúde. Sinasc 2014.

Nota-se no Gráfico 1 que a maior da parte da população elegível para solicitar a licença está entre 20 e 39 anos de idade, concentrando aproximadamente $85 \%$ dos pais. No total, para 2013, estima-se que 1,6 milhão de homens estariam aptos a solicitarem licença-paternidade.

Nas seções seguintes, a mesma equação (2) será utilizada para as estimativas da população elegível nos próximos anos. 0 emprego de projeções populacionais nesta equação leva às estimativas futuras da população elegível.

\section{Probabilidade de requisição da licença-paternidade}

Nas subseções anteriores chegou-se a um número de pessoas que poderão requerer o benefício da licença-paternidade. No entanto, ainda é necessário estimar qual é a probabilidade de o indivíduo (da população elegível) requerer a licença-paternidade. A PNAD 
permite identificar os trabalhadores que solicitaram licença remunerada do trabalho na semana de referência da pesquisa, mas não é possível saber o motivo da licença. Assim, a estimação da proporção de pais que requereram a licença partiu da comparação da proporção de licenças remuneradas para dois grupos de trabalhadores: grupo 1 (tratamento, ou $T=1$ ), composto por homens, na força de trabalho, formalizados, que tiveram filhos nos 12 meses anteriores à pesquisa; e o grupo 2 (controle, ou $T=0$ ), formado por homens, na força de trabalho, formalizados, que não tiveram filhos nos 12 meses anteriores à data de referência da pesquisa.

Para cada grupo de indivíduos, por faixa de idade, comparou-se a probabilidade de tirar licença remunerada (procedimento conhecido por pareamento na variável idade do indivíduo). Considera-se que a diferença entre os dois grupos seja dada, exclusivamente, pelo fato de o indivíduo do grupo 1 ter filho, ou seja, representa os casos que solicitaram licença-paternidade. Excluindo-se o percentual de licenças do grupo 1, espera-se controlar pelos outros motivos (que não seja o filho recém-nascido) que levaram os indivíduos a tirar licença (tais como doenças, greves), conforme demonstra a seguinte fórmula:

$\tau=P($ Licença $\mid T=1, X)-P($ Licença $\mid T=0, X)$

Em que: $X$ representa as características similares entre os dois grupos (trabalhadores do setor formal, com mesma idade).

Para chegar ao primeiro valor, utilizou-se a razão entre o total de homens pertencentes à PEA, que estão ocupados, no setor formal, tiveram filho no último mês da pesquisa (agosto de 2013) ${ }^{12}$ e se afastaram do trabalho na semana de referência e o total de homens pertencentes à PEA, que estão ocupados, no setor formal e que tiveram filho no último mês da pesquisa. Neste caso, o resultado foi de $2,174 \%$, representando o percentual de homens que tiveram filho em agosto e solicitaram a licença em alguma semana desse mês (grupo de tratamento). Para encontrar o segundo valor, utilizou-se o total de homens pertencentes à PEA, que estão ocupados, no setor formal, não tiveram filhos em 2013 e que se afastaram do trabalho na semana de referência dividido pelo total de homens pertencentes à PEA, que estão ocupados, no setor formal e não tiveram filhos em 2013. Com esse cálculo, chegou-se a um percentual de $0,27 \%$ de trabalhadores do sexo masculino do setor formal que não tiveram filhos no ano da pesquisa e solicitaram licença remunerada na semana de referência (grupo de controle). Como o dado só observa a semana de referência para os pais que tiveram filhos no mês, foi necessário multiplicar ambos os percentuais por 4 para se chegar à probabilidade de os pais requererem o benefício no mês. Logo, 1,08\% para o grupo de controle e $8,7 \%$ para o de tratamento.

Ao final, subtraiu-se o primeiro valor do segundo valor, estimando que o percentual de homens que solicitaram a licença remunerada pelo motivo de terem filho no período foi de $7,6 \%(\hat{\tau}=8,7 \%-1,08 \%)$.

\footnotetext{
$\overline{12}$ Na PNAD só é possível identificar o período exato em que o indivíduo foi pai no último mês da pesquisa, ou seja, em agosto de 2013.
} 
Esse percentual representa o impacto do filho na requisição da licença remunerada por parte do pai, ou a probabilidade de o pai requerer a licença remunerada por conta do nascimento do filho.

\section{Salário médio}

Uma vez estimada a população elegível que requererá a licença, é preciso encontrar o custo da licença a partir do salário dos indivíduos, que é considerado como a produtividade perdida pela empresa durante o período em que o trabalhador goza da licença-paternidade. Utilizou-se o salário médio, em termos de salários mínimos, da população de interesse por faixa etária (i) e período de análise $(t)$. Realizou-se este cálculo a partir das PNADs de 2008 a 2013, sempre com base na população elegível. A Tabela 1 apresenta o cálculo para cada um dos anos da pesquisa, assim como as médias mensal e diária.

TABELA 1

Salário médio da população elegível, com base no valor do salário mínimo, segundo faixas etárias Brasil - 2008-2013

\begin{tabular}{cccccccc}
\hline $\begin{array}{c}\text { Faixas etárias } \\
\text { (em anos) }\end{array}$ & $\mathbf{2 0 0 8}$ & $\mathbf{2 0 0 9}$ & $\mathbf{2 0 1 1}$ & $\mathbf{2 0 1 2}$ & $\mathbf{2 0 1 3}$ & $\begin{array}{c}\text { Média } \\
\text { mensal }\end{array}$ & $\begin{array}{c}\text { Média } \\
\text { diária }\end{array}$ \\
\hline $15-19$ & 1,66 & 1,77 & 1,76 & 1,81 & 1,80 & 1,76 & 0,06 \\
$20-24$ & 1,95 & 1,88 & 2,03 & 2,18 & 1,98 & 2,01 & 0,07 \\
$25-29$ & 2,69 & 3,45 & 2,62 & 2,61 & 2,45 & 2,77 & 0,09 \\
$30-34$ & 3,66 & 3,61 & 3,74 & 3,66 & 3,62 & 3,66 & 0,12 \\
$35-39$ & 4,26 & 3,42 & 4,35 & 3,67 & 4,41 & 4,02 & 0,13 \\
$40-44$ & 3,62 & 4,04 & 5,03 & 3,42 & 4,82 & 4,18 & 0,14 \\
$45-49$ & 4,71 & 3,94 & 4,09 & 6,12 & 3,09 & 4,39 & 0,15 \\
$50-54$ & 4,92 & 4,23 & 3,75 & 2,24 & 5,98 & 4,22 & 0,14 \\
$55-59$ & 3,19 & 6,80 & 3,10 & 4,20 & 3,68 & 4,19 & 0,14 \\
$60-64$ & 3,08 & 5,47 & 3,95 & 5,26 & 7,09 & 4,97 & 0,17 \\
\hline
\end{tabular}

Fonte: IBGE. PNADs 2008 a 2013.

Para o cálculo do salário diário em valores de reais de 2015, utiliza-se a média diária de cada faixa etária em salários mínimos e multiplica-se pelo salário mínimo de 2015 $(\mathrm{R} \$ 788,00)$.

\section{Resultados}

\section{Estimação docusto direto}

Conforme mostrado na seção anterior, o custo direto (CD), ou custo-salário, foi estimado de acordo com a seguinte fórmula:

$\hat{C D} \times \hat{\tau}\left(\sum_{\mathrm{i}=1}^{10}\left(P F_{i} \times P O F_{i} \times S M_{i} \times \Delta \times E C\right)\right.$ 
A partir da probabilidade de ter um filho em determinado ano, calcula-se a população elegível - número de trabalhadores formais que poderão requerer o benefício da licença-paternidade - para cada faixa etária. ${ }^{13}$ Para obter um valor monetário referente à perda de produtividade ocasionada por esses trabalhadores, adotou-se a premissa de que sua produtividade/dia (o valor que uma pessoa acrescenta à economia) é igual ao seu salário/dia. Como medida de salário, utilizou-se o rendimento diário de cada faixa etária das pessoas que tiveram filhos em 2013. Adicionalmente, esses valores foram ponderados por $E C=63,56 \%$, referente ao total de trabalhadores de empresas cujo regime tributário é de lucro real (de acordo com dados da Receita Federal do Brasil para 2013) e aos trabalhadores da administração pública. Como as empresas de lucro real podem deduzir o valor do benefício do montante devido de imposto de renda de pessoa jurídica, o incentivo fiscal é importante para a adesão dessas empresas ao Programa Empresa Cidadã e, portanto, para a futura solicitação do benefício pelos trabalhadores.

A estimativa obtida é, portanto, a medida de custo total, em termos de salário, caso todos os trabalhadores que tiverem filhos solicitem o benefício. Sobre esse valor, duas hipóteses foram relaxadas: consideraram-se diversos cenários de probabilidade de requerer a licença $(\hat{\tau})$; e consideraram-se diversos cenários de probabilidade de as empresas de lucro real aderirem ao Programa Empresa Cidadã (EC), o qual permite a dedução do benefício no imposto de renda das empresas de lucro real. Todos os valores calculados para os custos nos itens seguintes são em reais de 2015. Logo, não são levados em conta possíveis reajustes salariais e a taxa de inflação.

\section{Custo direto total: cenários de solicitação da licença}

A Tabela 2 apresenta os resultados para os diversos cenários de custo direto para a economia brasileira ao longo dos próximos 15 anos, segundo as probabilidades de solicitar a licença-paternidade, supondo-se que todas as empresas sob o regime de tributação de lucro real aderissem ao Empresa Cidadã. Como é possível observar, se o aumento de 5 para 20 dias da licença-paternidade começasse a vigorar a partir de 2016, pela probabilidade de requisição calculada de $7,6 \%$, o custo seria de $R \$ 100,6$ milhões. Se todos que pudessem requerer a licença-paternidade o fizessem, o custo total para a economia (num dado ano) seria de pouco mais de $\mathrm{R} \$ 1,32$ bilhão. Em todos os cenários calculados, o custo seria crescente até 2024 e, a partir deste ano, devido à mudança demográfica do país, o custo começaria a decrescer até 2030.

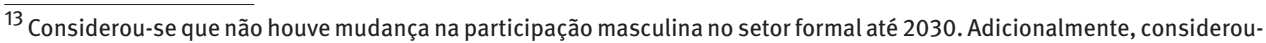
se a mesma probabilidade de os homens terem filhos no período da projeção, o que pode superestimar o custo para os períodos subsequentes, visto que a taxa de fecundidade feminina apresenta diminuição no período e, provavelmente, os homens também. Por outro lado, a mortalidade apresenta declínio.
} 
TABELA 2

Custo direto de solicitação da licença-paternidade, segundo probabilidades de requisição da licença Brasil - 2016-2030

\begin{tabular}{lrrrrrrrr}
\hline $\begin{array}{c}\text { Probabilidades } \\
\text { de requerer a } \\
\text { licença }\end{array}$ & $\mathbf{2 0 1 6}$ & $\mathbf{2 0 1 8}$ & $\mathbf{2 0 2 0}$ & $\mathbf{2 0 2 2}$ & $\mathbf{2 0 2 4}$ & $\mathbf{2 0 2 6}$ & $\mathbf{2 0 2 8}$ & $\mathbf{2 0 3 0}$ \\
\hline $5 \%$ & 66,2 & 66,9 & 67,4 & 67,7 & 67,8 & 67,8 & 67,6 & 67,3 \\
$7,6 \%$ & 100,6 & 101,8 & 102,5 & 102,9 & 103,0 & 103,0 & 102,8 & 102,3 \\
$10 \%$ & 132,4 & 133,9 & 134,9 & 135,4 & 135,6 & 135,5 & 135,2 & 134,6 \\
$20 \%$ & 264,8 & 267,8 & 269,8 & 270,9 & 271,1 & 271,0 & 270,4 & 269,2 \\
$30 \%$ & 397,1 & 401,7 & 404,7 & 406,3 & 406,7 & 406,5 & 405,6 & 403,8 \\
$50 \%$ & 661,9 & 669,4 & 674,4 & 677,2 & 677,8 & 677,5 & 676,1 & 673,0 \\
$70 \%$ & 926,6 & 937,2 & 944,2 & 948,1 & 948,9 & 948,5 & 946,5 & 942,2 \\
$100 \%$ & $1.323,8$ & $1.338,9$ & $1.348,9$ & $1.354,4$ & $1.355,6$ & $1.355,0$ & $1.352,1$ & $1.346,0$ \\
\hline
\end{tabular}

Fonte: IBGE. PNADs 2008 a 2013 e Projeções Populacionais 2014 a 2030; Ministério da Saúde. Sinasc 2014; Receita Federal do Brasil. Receitadata 2008 a 2012.

\section{Custo direto total: cenários de adesão ao Empresa Cidadã}

Nesta seção, relaxou-se a hipótese feita anteriormente de que $100 \%$ das empresas de regime de lucro real adeririam ao Programa Empresa Cidadã. Para a probabilidade de requerer a licença, considerou-se o percentual de 7,6\%.

TABELA 3

Custo direto de solicitação da licença-paternidade, segundo probabilidades de adesões ao Programa Empresa Cidadã

Brasil - 2016-2030

Em R\$ milhões de 2015

\begin{tabular}{lrrrrrrrr}
\hline $\begin{array}{c}\text { Probabilidade de aderir } \\
\text { ao Empresa Cidadã }\end{array}$ & $\mathbf{2 0 1 6}$ & $\mathbf{2 0 1 8}$ & $\mathbf{2 0 2 0}$ & $\mathbf{2 0 2 2}$ & $\mathbf{2 0 2 4}$ & $\mathbf{2 0 2 6}$ & $\mathbf{2 0 2 8}$ & $\mathbf{2 0 3 0}$ \\
\hline $5 \%$ & 5,0 & 5,1 & 5,1 & 5,1 & 5,2 & 5,1 & 5,1 & 5,1 \\
$10 \%$ & 10,1 & 10,2 & 10,3 & 10,3 & 10,3 & 10,3 & 10,3 & 10,2 \\
$20 \%$ & 20,1 & 20,4 & 20,5 & 20,6 & 20,6 & 20,6 & 20,6 & 20,5 \\
$30 \%$ & 30,2 & 30,5 & 30,8 & 30,9 & 30,9 & 30,9 & 30,8 & 30,7 \\
$40 \%$ & 40,2 & 40,7 & 41,0 & 41,2 & 41,2 & 41,2 & 41,1 & 40,9 \\
$50 \%$ & 50,3 & 50,9 & 51,3 & 51,5 & 51,5 & 51,5 & 51,4 & 51,1 \\
$60 \%$ & 60,4 & 61,1 & 61,5 & 61,8 & 61,8 & 61,8 & 61,7 & 61,4 \\
$70 \%$ & 70,4 & 71,2 & 71,8 & 72,1 & 72,1 & 72,1 & 71,9 & 71,6 \\
$80 \%$ & 80,5 & 81,4 & 82,0 & 82,3 & 82,4 & 82,4 & 82,2 & 81,8 \\
$90 \%$ & 90,5 & 91,6 & 92,3 & 92,6 & 92,7 & 92,7 & 92,5 & 92,1 \\
$100 \%$ & 100,6 & 101,8 & 102,5 & 102,9 & 103,0 & 103,0 & 102,8 & 102,3 \\
\hline
\end{tabular}

Fonte: IBGE. PNADs 2008 a 2013 e Projeções Populacionais 2014 a 2030; Ministério da Saúde. Sinasc 2014; Receita Federal do Brasil. Receitadata 2008 a 2012.

Note-se que, para todos os cenários, os valores se mantêm relativamente estáveis ao longo do tempo, de modo que a variabilidade advém predominantemente da diferença entre as taxas de adesão. Desse modo, observa-se que um crescimento de $10 \%$ na taxa de 
adesão ao programa resultaria em um aumento no custo direto total de aproximadamente R\$ 10 milhões.

\section{Custo versus arrecadação}

O cenário mais provável de custo, em termos de salário, é aquele em que se considera a requisição da licença-paternidade de $7,6 \%$ dos trabalhadores formais que terão filhos num determinado ano. Ainda assim, de acordo com a hipótese bastante conservadora de que $100 \%$ das empresas aderissem ao Programa Empresa Cidadã, verifica-se que o custo anual estaria em torno de $\mathrm{R} \$ 100$ milhões. Comparando-se esse valor com a arrecadação federal total, levando em conta que o governo federal renunciaria a parte do imposto de renda a ser recolhido pelas Empresas Cidadãs, tem-se que tal custo representa cerca de $0,01 \%$ do total arrecadado pelo governo federal em 2014 . Em contrapartida, ao se assumir que as empresas absorveriam tal benefício, o custo estimado representaria 0,0002\% do valor adicionado, a preços básicos, gerado pela economia brasileira em 2014.

\section{Considerações finais}

Desde a Constituição Federal de 1988, e até recentemente, os homens tinham o direito a cinco dias de licença-paternidade no Brasil. A Lei n. 13.257/2016, conhecida por "Marco Legal da Primeira Infância", faculta aos pais a prorrogação por 15 dias adicionais da licença-paternidade.

Pouco se sabe sobre o impacto dessas medidas - seus custos e benefícios - ao longo do tempo. Os poucos estudos existentes sobre os potenciais benefícios da licença-paternidade na vida da família e, especificamente, do recém-nascido encontram, todavia, evidência de impactos importantes. Três efeitos foram identificados na literatura: aumento do período de amamentação dos bebês (cujos retornos no longo prazo já são bem conhecidos e documentados na literatura médica); maior envolvimento futuro dos pais no cuidado com as crianças, o que pode ter importantes consequências no desenvolvimento sociocognitivo dos filhos e filhas; e provável auxílio na promoção da igualdade de gêneros dentro das atividades familiares (a partir da maior inclusão dos pais nas tarefas domésticas e cuidado com os filhos, ainda fortemente dependente das mulheres).

Em que pesem os supostos benefícios, além de estar na agenda de direitos reconhecida internacionalmente, conjectura-se teoricamente que a concessão desse tipo de benefício ao trabalhador pode ter custos significativos, podendo - a depender da extensão do benefício - provocar uma redução no rendimento e nível de emprego. A investigação da literatura empírica sugere, entretanto, que esses custos seriam pequenos no caso da ampliação da licença-paternidade em consideração no Brasil: esse tipo de efeito foi observado apenas em países onde a licença é relativamente extensa (pelo menos 30 dias), como no caso da Noruega (O’BRIEN, 2009; REGE; SOLLI, 2013). O fato é que pouco ou quase nada se sabe ainda sobre os custos da extensão da licença-paternidade para o Brasil. 
Esse estudo trouxe elementos para preencher essa lacuna no que se refere a custos econômicos. Assim, o custo, em termos de salário, da ampliação de 15 dias na licença-paternidade é estimado. Ressalta-se que, neste artigo, não foram apresentadas estimativas dos benefícios que potencialmente podem ser trazidos pela medida, apenas uma estimativa dos custos econômicos diretos.

As estimativas consideram, seguindo os termos da lei, que o benefício seria facultado apenas para os trabalhadores das empresas que aderirem ao Programa Empresa Cidadã. Em uma série de cenários que utilizam os parâmetros do mercado de trabalho atual e as projeções da população para os próximos anos, estimou-se que o custo direto da política pode variar de $\mathrm{R} \$ 5$ milhões a pouco mais de $\mathrm{R} \$ 100$ milhões, dependendo do cenário considerado.

Esse estudo fornece, portanto, indicações de que a extensão da licença-paternidade nos termos considerados constitui uma política social de baixo custo, embora não seja possível verificar o custo-efetividade da política neste momento. 0 período de licença-paternidade ainda é pouco extenso na maior parte do mundo para que seus benefícios sejam adequadamente mensurados. Inexistem no Brasil, até onde se sabe, estudos sobre os benefícios da duração da licença-paternidade em voga. Assim, as poucas evidências são provenientes de países onde essas licenças são mais extensas e estão em funcionamento há mais tempo. Como os custos estimados para a ampliação da licença proposta são relativamente muito baixos, é provável que os benefícios - que devem ser similares, ao menos qualitativamente, aos informados pela evidência internacional existente - sejam suficientes para mais do que compensar seus custos econômicos diretos. Essa é, no entanto, uma pergunta empírica ainda a ser investigada, assim como devem ser analisados em conjunto os custos e benefícios da licença-maternidade - tanto os econômicos diretos quanto os indiretos -, desde que a agenda de igualdade de direitos se aplica aos homens e às mulheres participantes do mercado de trabalho, abrindo uma agenda de pesquisa importante no Brasil.

\section{Referências}

ADDATI, L.; CASSIRER, N.; GILCHRIST, K. Maternity and paternity at work: law and practice across the world. [S.I.]: International Labour Office, 2014.

BAKER, M.; MILLIGAN, K. How does job-protected maternity leave affect mothers' employment? Journal of Labor Economics, v. 26, n. 4, p. 655-691, 2008.

BAUM, C. L. The effects of maternity leave legislation on mothers' labor supply after childbirth. Southern Economic Journal, v. 69, n. 4, p. 772-799, 2003.

BERGER, L. M.; HILL, J.; WALDFOGEL, J. Maternity leave, early maternal employment and child health and development in the US. The Economic Journal, v. 115, n. 501, p. F29-F47, 2005.

CARVALHO, S. S. D. Os efeitos da licença maternidade sobre salário e emprego da mulher no Brasil. Rio de Janeiro: PUC-Rio, 2005. 
CHACKIEL, J.; ORELLANA, $\mathrm{H}$. Adult female mortality trends from retrospective questions about maternal orphanhood included in censuses and surveys. In: INTERNATIONAL POPULATION CONFERENCE, Florence, 1985. Anais... Liége, Belgium: International Union for the Scientific Study of Population (IUSSP), v. 4, 1985.

COOLS, S.; FIVA, J. H.; KIRKEB ØEN, L. J. Causal effects of paternity leave on children and parents. The Scandinavian Journal of Economics, v. 117, n. 3, p. 801-828, 2015.

ESCOT, L.; FERNÁNDEZ-CORNEJO, J. A.; POZA, C. Fathers' use of childbirth leave in Spain. The effects of the 13-day paternity leave. Population Research Review, v. 33, n. 3, p. 419-453, 2015.

FLACKING, R.; DYKES, F.; EWALD, U. The influence of fathers' socioeconomic status and paternity leave on breastfeeding duration: a population based cohort study. Scandinavian Journal of Public Health, n. 38, p. 337-343, 2010.

FREJKA, T.; JONES, G. W.; SARDON, J. East Asian childbearing patterns and policy developments. Population and Development Review, v. 35, n. 3, p. 579-606, 2010.

GISLASON, I. V. Parental leave in Iceland. Bringing the fathers in. Akureyri: Center for Gender Equality, Ministry of Social Affair of Iceland, 2007.

GRUBER, J. The incidence of mandated maternity benefits. The American Economic Review, V. 84, n. 3, p. 622-641, 1994.

HAATAJA, A. Fathers' use of paternity and parental leave in the Nordic countries. Helsinki: The Social Insurance Institution og Finland (Kela), Research Departement, 2009 (Online working papers, 2/2009).

HAN, W.-J.; RUHM, C.; WALDFOGEL, J. Parental leave policies and parents' employment and leavetaking. Journal of Policy Analysis and Management, v. 28, n. 1, p. 29-54, 2009.

HUERTA, M. D. C. et al. Fathers' leave, fathers' involvement and child development. Paris: OECD, 2013 (OECD Social, Employment and Migration Working Paper, n. 140).

KAROLY, L. A.; KILBURN, M. R.; CANNON, J. S. Early childhood interventions: proven results, future promise. Santa Monica, CA: RAND Corporation, 2005.

KOTSADAM, A.; FINSERAAS, $\mathrm{H}$. The state intervenes in the battle of the sexes: causal effects of paternity leave. Social Science Research, v. 40, n. 6, p. 1611-1622, 2011.

LEQUIEN, L. The impact of parental leave duration on later wages. Annals of Economics and Statistics, n. 107, p. 267-285, 2012.

NEPOMNYASCHY, L.; WALDFOGEL, J. Paternity leave and fathers' involvement with their young children: evidence from the American Ecls-B. Community, Work and Family, v. 10, n. 4, p. 427453, 2007.

O’BRIEN, M. Fathers, parental leave policies, and infant quality of life: international perspectives and policy impact. The Annals of the American Academy of Political and Social Science, v. 624, n. 1, p. 190-213, 2009.

OIT - Organização Internacional do Trabalho. Trabalho e família: rumo a novas formas de conciliação com corresponsabilidade social. Brasília: OIT, 2009.

REGE, M.; SOLLI, I. F. The impact of paternity leave on fathers' future earnings. Demography, V. 50, n. 6, p. 2255-2277, 2013.

RUHM, C. J. The economic consequences of parental leave mandates: lessons from Europe. [S.I.]: National Bureau of Economic Research, 1996. 
SORJ, B.; FONTES, A.; MACHADO, D. Políticas e práticas de conciliação entre família e trabalho no Brasil. Cadernos de Pesquisa, v. 37, n. 132, p. 573-594, 2007.

STAEHELIN, K.; BERTEA, P. C.; STUTZ, E. Z. Length of maternity leave and health of mother and child - a review. International Journal of Public Health, v. 52, n. 4, p. 202-209, 2007.

THOR ARNARSON, B.; MITRA, A. The paternity leave act in Iceland: implications for gender equality in the labour market. Applied Economics Letters, v. 17, n. 7, p. 677-680, 2010.

UGRENINOV, E. Can family policy reduce mothers' sick leave absence? A causal analysis of the Norwegian paternity leave reform. Journal of Family and Economic Issues, v. 34, n. 4, p. 435-446, 2013.

VICTORA, C. G. et al. Breastfeeding and school achievement in Brazilian adolescents. Acta Paediatrica, v. 94, n. 11, p. 1656-1660, 2005.

Association between breastfeeding and intelligence, educational attainment, and income at 30 years of age: a prospective birth cohort study from Brazil. The Lancet Global Health, v. 3, n. 4, p. 199-205, 2015.

ZIGLER, E. F. E. A. A vision for universal preschool education. Cambridge, MA: Cambridge University Press, 2006.

\section{Sobre os autores}

Sergio Almeida é doutor em Economia pela Universidade de Nottingham na Inglaterra. É professor do Departamento de Economia da Faculdade de Economia, Administração e Contabilidade da Universidade de São Paulo (FEA-USP).

Paula Pereda é economista, doutora em Ciências Econômicas e mestre em Teoria Econômica pela Universidade de São Paulo. É professora do Departamento de Economia da Faculdade de Economia, Administração e Contabilidade da Universidade de São Paulo (FEA-USP).

Rafael Xavier é doutor e mestre pela Escola de Pós-Graduação em Economia (EPGE) da Fundação Getulio Vargas (FGV). É professor e pesquisador na Faculdade de Economia, Administração e Contabilidade da Universidade de São Paulo (FEA-USP).

\section{Endereço para correspondência:}

Sergio Almeida

Faculdade de Economia, Administração e Contabilidade da Universidade de São Paulo Avenida Professor Luciano Gualberto, 908

FEA 2 - sala 235, Butantã

05508-010 - São Paulo-SP, Brasil

Paula Pereda

Faculdade de Economia, Administração e Contabilidade da Universidade de São Paulo Avenida Professor Luciano Gualberto, 908

FEA 2 - sala 218, Butantã

05508-010 - São Paulo-SP, Brasil

Rafael Ferreira

Faculdade de Economia, Administração e Contabilidade da Universidade de São Paulo Avenida Professor Luciano Gualberto, 908

FEA 2, Butantã

05508-010 - São Paulo-SP, Brasil 


\begin{abstract}
Costs of the extension of the paternity leave in Brazil

There is a growing empirical literature documenting that quality in early education and parental care are associated with better emotional and cognitive development later in life. With this in mind, governments in several countries have changed labor laws in order to give more employment security for parents of the newborns aiming to give financial and legal support (employment protection). A law recently passed in Brazil has increased paternity leave from 5 to 20 working days of paid leave (Marco da Primeira Infância, Law 13.257/2016). Little is known, however, about the economic impacts of such a law. This paper aims at quantifying the costs of such increase in paternity leave. By utilizing the annual household survey microdata (Pesquisa Nacional por Amostra de Domicílios), some labor market indicators and a population projections series it is calculated fathers' probability of claiming paternity benefits. Several long-range forecasts about the costs implementation produced. The results indicates that the increase in paid paternity leave, due to this change in the law, has relatively low cost - around 100 million Brazilian reais per year in the most likely scenario, an amount that is $0.01 \%$ of federal revenues in 2014. While the benefits of increasing paid paternity leave are still unknown in Brazil, the results suggest that this kind of intervention is likely to be cost-effective.
\end{abstract}

Keywords: Paternity leave. Early childhood. Costs.

\title{
Resumen
}

Los costos de la ampliación del permiso de paternidad en Brasil

Existe una creciente documentación en la literatura empírica sobre la asociación entre la educación de calidad y el cuidado de los padres con un mejor desarrollo emocional y cognitivo de los niños. Por lo tanto, los gobiernos de varios países promueven cambios en sus leyes laborales destinadas al apoyo financiero y legal (protección del empleo) para madres y padres con hijos recién nacidos. Brasil aprobó recientemente el Marco da Primeira Infância (Ley 13.257/2016) que amplió el permiso parental de cinco a veinte días. Sin embargo, poco se sabe sobre el impacto económico de este tipo de política pública. Este artículo pretende cuantificar los costos de la extensión temporal del permiso de paternidad. A partir de datos de la Pesquisa Nacional por Amostra de Domicilios, de indicadores del mercado de trabajo y de las proyecciones de población, se estimó el costo de la extensión del permiso. Los resultados indican que el costo de esta ampliación de la licencia es bajo - cerca de $R \$ 100$ millones por año en el escenario más probable, lo que representa $0,01 \%$ de los ingresos federales en 2014-. Aunque la magnitud de los beneficios de este tipo de intervención sea desconocida en Brasil, los resultados muestran que es probable que sea costo-efectiva.

Palabras clave: Permiso de paternidad. Primera infancia. Costos.

Recebido para publicação em 02/02/2016

Recomendado para publicação em 04/08/2016

Aceito para publicação em 13/11/2016 